\title{
Reducing the probability of ship grounding: which measure to undertake?
}

\author{
Muhammad Juned Akhtar • Ingrid Bouwer Utne
}

Received: 27 May 2013 / Accepted: 26 August 2013 /Published online: 10 September 2013

(C) World Maritime University 2013

\begin{abstract}
The analytic hierarchy process has been used to elicit the knowledge of maritime transport stakeholders, such as seafarers, authorities, insurers and academics, regarding human factors and risk-reducing measures for ship groundings. Measures against human fatigue, alcohol abuse, language barriers, poor bridge management and safety climate have been compared with regard to costs and benefits. The measures are discussed in the context of large ships on a voyage of at least $24 \mathrm{~h}$ containing Bridge Resource Management. The study shows that stakeholders consider the costs of the measures to reduce human fatigue at sea surpass the benefits. Measures against alcohol abuse are regarded as the most cost-benefit efficient. Also, the stakeholders consider the watch scheme 8-4-4-8 to be less fatiguing than the 12-12 watch scheme. In addition, the results of the study support previous findings that inadequate manning levels contribute the most to human fatigue within the bridge management team.
\end{abstract}

Keywords Analytic hierarchy process $\cdot$ Human factors $\cdot$ Human fatigue $\cdot$ Cost-benefit analysis · Ship groundings

\section{Introduction}

The bridge of a large ship is full of complex systems interacting with each other. It takes years of training and experience for an operator to fully master them. The degree to which human factors, such as fatigue, affect performance can vary from negligible to catastrophic. Even though the exact causality is not yet fully grasped, it is well understood that human fatigue contributes to accidents at sea (Lützhöft et al. 2007; Xhelilaj and Lapa 2010; MacDonald 2006). Unlike impairment caused by alcohol or drugs, which can be measured by blood tests, human fatigue is more difficult to explicitly measure and is

\footnotetext{
M. J. Akhtar $(\bowtie)$

Institute of Transport Economics (TØI), Gaustadalleen 21, NO-0349 Oslo, Norway

e-mail: jak@toi.no

I. B. Utne

Department of Marine Technology, Norwegian University of Science and Technology (NTNU),

Trondheim, Norway
} 
often only inferred as an underlying cause of an accident (Desmond and Hancock 2001; IMO 2001; Sneddon et al. 2012; Xhelilaj and Lapa 2010).

Seafarers may be required to work at sea for several days with unpredictable working times and workloads. This period can include tight schedules, circadian effects and efficiency pressure (Cahill 2002; Perrow 1984; Celik and Cebi 2009). The maritime community is concerned about seafarers' fatigue levels, which is considered to be higher than that experienced by onshore workers (Smith et al. 2006; Seahealth 2010; Graham 2009).

The presence of human fatigue within a bridge management team (BMT) depends on several factors. A fatigued BMT has a higher probability of grounding the ship than a non-fatigued team (Macrae 2009). The US Coast Guard Research and Development Centre estimates fatigue to be the primary contributor to $16 \%$ of vessel casualties (Rothblum et al. 2002). Great Britain's Department of Transportation concluded in a study that about $33 \%$ of the groundings involved a fatigued officer alone on the bridge (Xhelilaj and Lapa 2010). For land transport on motorways and major roads, fatigue is cited as being responsible for up to $20 \%$ of accidents (Williamson et al. 2009).

In this article, maritime domain stakeholders' knowledge of human fatigue, as well as the costs and benefits of measures to reduce the probability of ship groundings, has been elicited through the analytic hierarchy process (AHP). In general, stakeholder elicitation is known to be a delicate task, as it involves transforming subjective opinions into objective and quantitative probabilities. Such probabilities may be used to prioritize measures and investments.

It is clear that deciding upon measures that influence a complex social technical system, such as the maritime transport system, is not a straightforward matter. A number of organizational and human factors influence the behaviour of seafarers. This is a fact which is not always given enough attention when considering safety measures (SchröderHinrichs et al. 2012). However, the AHP is a suitable tool for analysing complex problems such as human fatigue and its effect on the probability of ship grounding. When choosing between a range of options, the AHP method gives decision-makers an overview of the various possibilities. The method also ranks the options by quantifying the tacit knowledge the stakeholders hold in relation to a goal, i.e. the method helps to quantify the unspoken and intuitive thinking of people (Saaty 2001). As such, AHP is widely used in various disciplines where decision-making is difficult because of a problem's many dimensions (Saaty and Vargas 2006; Zheng et al. 2012; Vidal et al. 2010; Bûyûkôzkan et al. 2011; Utne 2008).

Most people, including experts, find it difficult to formulate single-event probabilities. The easiest way to elicit a probability is to just ask for a number. However, even experts may be reluctant and feel uneasy when they are asked to provide exact figures. This is especially true for intangible elements like human fatigue. Therefore, various verbal mapping schemes have been developed (Anderson et al. 2003; Greenberg 2007; Saaty 2004). Mapping schemes work well because humans have the ability to perceive relationships among the things they observe and to compare pairs of similar things or elements against certain criteria. In AHP, each decision element is compared in pairs, and thus relationships between the elements can be established (Saaty 2001).

Cost-benefit analysis (CBA) is widely used in various fields to assess the impacts of investments. CBA can be used to decide whether to undertake specific projects, the selection of the most productive measures or even to maximize the total benefits 
(Elvik 2001; Veisten and Akhtar 2010; Saaty and Vargas 2006; Gujiter and Hageman 2010; Saaty 2001). AHP can be utilized for CBA, but it is important to ensure that the benefits and cost priorities are not derived from separate hierarchies (Wedley et al. 2001). TL Saaty (2001) used this method for a number of cases, for instance, deciding on a home computer and selecting a portfolio for a corporation. Aziz (1990) used AHP combined with CBA to evaluate a highway project. The combined method was used to determine whether the benefits would outweigh the costs of allowing gambling on a riverboat (Clayton and Wright 1993). However, to the authors, knowledge, this is the first time the combined AHP and CBA method has been used to rank measures related to human factors.

The objective of this article is to compare measures for reducing the probability of ship groundings regarding five different human and organizational factors. The article presents an approach by which the results from AHP may be used to conduct CBA of measures related to alcohol abuse, human fatigue, language barriers, bridge resource management and safety climate. ${ }^{1}$ Stakeholders have been asked to compare the costs of the measures with their assumed benefits for a ship on a voyage of at least $24 \mathrm{~h}$ containing bridge resource management. The AHP calculations are done to rank the measures according to their cost-benefit ratios. The study detects differences between the various stakeholders, as well as their prioritization of the measures. To elicit stakeholders' understanding and knowledge about human fatigue specifically, the study also focuses on six major human fatigue-related factors. Based on AHP, these factors can be ranked according to their relative importance.

The remainder of this article is organized as follows: Section 2 explains the AHP method and the three AHP models developed for this study. It also accounts for the data collection. Section 3 presents the results and a cost-benefit analysis. Section 4 discusses the results and the conclusions.

\section{The analytic hierarchy process}

Figure 1 shows the AHP method in five steps: (1) determine the objective of the analysis, (2) structure the problem at hand into a hierarchical model consisting of elements related to the decision to be made, (3) ask the experts and/or stakeholders to choose between the decision elements so as to reflect their preferences, (4) derive the relative priorities, i.e. the order the decision elements are prioritized by the experts, and (5) assess the validity of the results in terms of a consistency score.

\subsection{Constructing AHP models}

No exact rule exists for constructing AHP hierarchies or models. The top level should be a single element reflecting the purpose of the analysis. The decision elements (up to seven) in the subsequent levels should enable a comparison in relation to the higher level (Saaty 2001). The limitation of seven elements is done because human beings have limited capacity to process information simultaneously with reliable accuracy and validity (Saaty and Ozedemir 2003).

\footnotetext{
${ }^{1}$ See the Annex.
} 


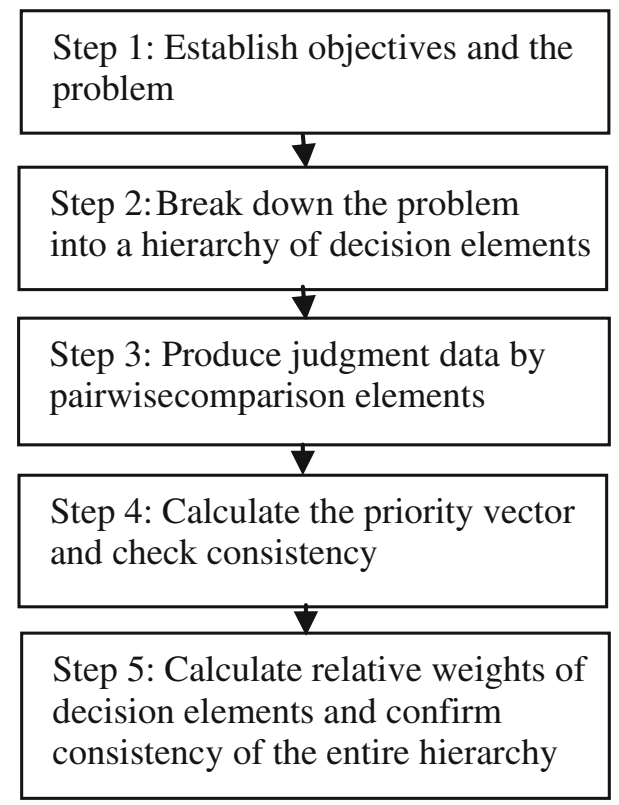

Fig. 1 AHP process (adapted from Yang and Shi 2002)

A scale from 1 to 9, reflecting the relative strength of preferences, is most commonly used to elicit the comparisons (Saaty 1987). The fundamental scale normally used in AHP studies represents the judgments made in pairwise comparisons (Table 1) (Saaty and Vargas 2006). Comparisons of the decision elements are organized into matrices from which eigenvectors (also called the relative value vectors) are computed. These eigenvectors are interpreted as the relative priorities. If several experts are involved, the geometric mean may be used to find the averages of the judgments before calculating the eigenvectors. The mathematics are thoroughly discussed in the literature (Saaty 2004, 2001; Saaty and Vargas 2006; Arslan and Turan 2009). A good consistency (a score $<0.1$ )

Table 1 The fundamental scale of values (Saaty 2001)

\begin{tabular}{|c|c|c|}
\hline Intensity of importance & Definition & Explanation \\
\hline 1 & Equal importance & Two activities contribute equally to the objective \\
\hline 3 & Moderate importance & $\begin{array}{l}\text { Experience and judgement slightly favour one } \\
\text { activity over another }\end{array}$ \\
\hline 5 & Strong importance & $\begin{array}{l}\text { Experience and judgement strongly favour one } \\
\text { activity over another }\end{array}$ \\
\hline 7 & $\begin{array}{l}\text { Very strong demonstrated } \\
\text { importance }\end{array}$ & $\begin{array}{l}\text { An activity is favoured very strongly over another; } \\
\text { its dominance is demonstrated in practice }\end{array}$ \\
\hline 9 & Extreme importance & $\begin{array}{l}\text { The evidence favouring one activity over another is } \\
\text { of the highest possible order of affirmation }\end{array}$ \\
\hline $2,4,6,8$ & $\begin{array}{l}\text { Intermediate values to } \\
\text { reflect compromise }\end{array}$ & \\
\hline
\end{tabular}


shows that the expert's judgement does not appear to be random and shows the relationships between AHP process (Fig. 1) and the fundamental scale of values (Table 1).

\subsection{Ship grounding and the human fatigue models}

In the present study, three AHP hierarchies (models) have been constructed. Models 1 and 2 analyse various elements in the BMT. They are made up of five elements, which all represent different measures for reducing the probability of ship grounding. Model 3 is specifically focused on human fatigue; it is made of the six elements which are known to influence human fatigue. The context for all the models is ships at sea for more than $24 \mathrm{~h}$.

\subsubsection{The ship grounding models}

It could be argued that there are hundreds of different factors influencing the probability of ship groundings. Fortunately, research exists which structures and classifies those which are thought to be the most important. The AHP method recommends a maximum of seven comparative factors or elements at one time, and they should all satisfy three basic requirements: independency, understandability and distinctiveness (Saaty 2001).

Akhtar and Utne ${ }^{2}$ introduce a modified human factor analysis and classification system (HFACS) for maritime groundings. HFACS is a framework for classifying the states and actions that can lead to an accident (Wiegmann and Shapell 2003; Chauvin et al. 2013). Based upon the modified HFACS (see Fig. 2) and a literature review, five measures were selected for the AHP study in this article: namely measures against alcohol misuse, human fatigue and language barriers and measures to improve bridge resource management (BRM) and the safety climate. ${ }^{3}$

Akhtar and Utne organized 63 commonly known fatigue-related factors into the HFACS structure. They further constructed a Bayesian network $(\mathrm{BN})$ using data from 93 accident investigation reports. It was estimated that a fatigued operator raises the probability of grounding for a large ship in long transit by $16 \%$. The probability of a watchkeeper being fatigued was found to be $23 \%$. However, the importance of fatigue measured in relation to other human and organizational factors suggested by the maritime community was outside the scope of the study. Since it is important to elicit the views of the stakeholders, and compare them to the available statistics and data available, the decision elements in the AHP models are derived from the $\mathrm{BN}$ in Akhtar and Utne. It is also important to include stakeholders because accident investigation reports do not always recognize organizational factors as major safety factors in maritime accidents (Schröder-Hinrichs et al. 2011).

Furthermore, the elements in the AHP models in this article are all subject to much discussion in the scientific literature. Alcohol misuse is a problem in maritime transport, and it also amplifies human fatigue levels (Cuculic et al. 2009; Marsden and Leach 2000; Howland et al. 2001). Even low alcohol exposure significantly impairs the performance of navigators (Howland et al. 2001). A period of sustained wakefulness of $18 \mathrm{~h}$ can be comparable to a blood alcohol concentration (BAC) of $0.05 \%$. Various scientific research papers regard

\footnotetext{
${ }^{2}$ Akhtar, J., \& Utne, I. B. (2013a). An analysis of common patterns in aggregated accident analysis charts from human fatigue-related groundings and collisions at sea. Submitted (Marit Polic \& Manag).

${ }^{3}$ More detailed explanations of the elements can be found in the Annex.
} 


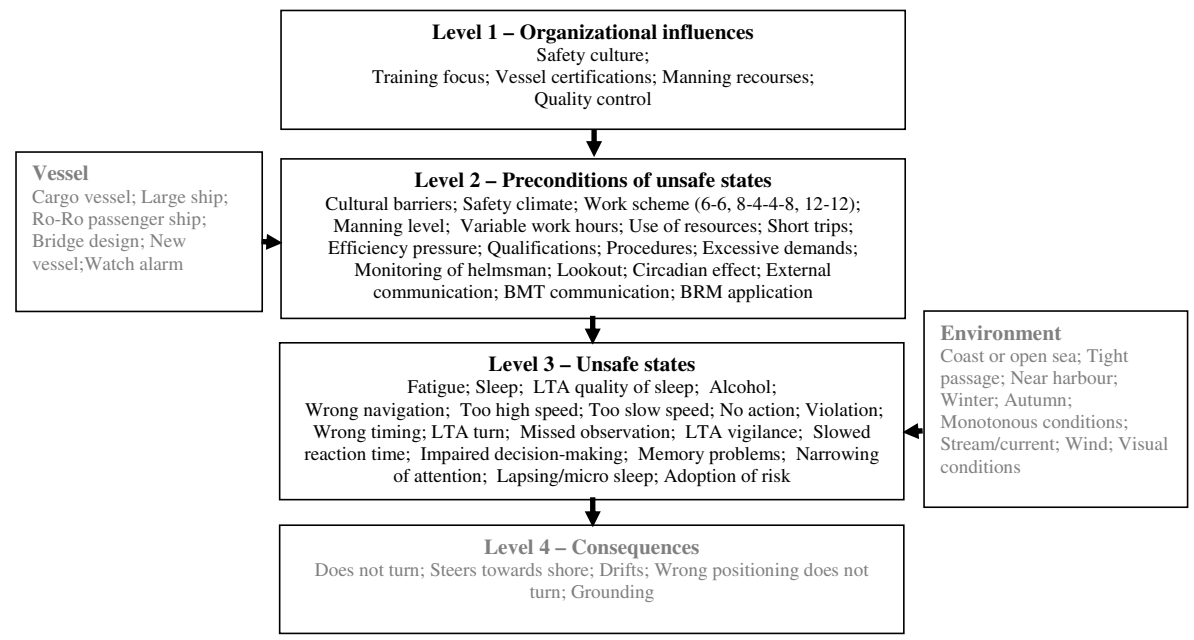

Fig. 2 Modified HFACS methodology, including the human fatigue-related factors identified from the examination of the accident investigation reports (See footnote 4)

the safety climate as vital with regard to human fatigue ( $\mathrm{Lu}$ and Tsai 2008; Neal et al. 2000; Strahan et al. 2008; Schröder-Hinrichs et al. 2012). BRM is regarded as important for safe navigation and may also impact human fatigue (Cahill 2002; Swift 2004; MAIB 2004; Blom 2006). Lastly, language is important for clear communication and is seen as the glue which keeps all the safety procedures on the bridge in place (Perrow 1984; Hänninen 2008; Rothblum et al. 2002; Cahill 2002; Barnett 2005).

Figure 2 modified HFACS methodology, including the human fatigue-related factors identified from the examination of the accident investigation reports. ${ }^{4}$

\subsubsection{Human fatigue model}

Another different set of elements known to have an influence on human fatigue were selected for model 3. Less than adequate (LTA) vessel certification (i.e. certification(s) or legal paper(s) are missing or outdated) is believed to affect the working environment, including human fatigue and the attitude the crew has towards safety on-board (IMO 2001, 2011; Health \& Safety Executive 2005; Lappalainen 2008). LTA efficiency pressure and LTA manning levels are believed to have a high influence on human fatigue (IMO 1999; Dorrian et al. 2011; MacDonald 2006; Progoulaki and Roe 2011; Schröder-Hinrichs et al. 2012). Short trips, the two-watch schemes systems (8-4-4-8 and 12-12) and safety climate were also included as elements because they are all subject to much debate concerning their influence on human fatigue in the research literature (Åkerstedt $\mathrm{T}$ et al. 2000; QinetiQ Centre 2006; Lützhöft et al. 2007; Ficca et al. 2010; Ridefelt et al. 2010).

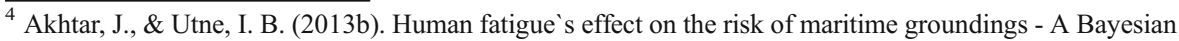
Network modelling approach. Submitted (Safety Science).
} 


\subsection{Pairwise comparisons}

Decision-makers often have many favourable and unfavourable concerns to consider: the favourable concerns can be defined as benefits, while the unfavourable concerns can be defined as costs (Saaty and Vargas 2006).

Model 1 focuses on which measures the stakeholders believe are the most effective to decrease the probability of ship grounding (Fig. 3). Model 2 shows the relative expected capital costs of the measures (Fig. 4). Model 3 is made up of six elements (Fig. 5) and ranks the decision elements according to how the stakeholders' perceive their impact on human fatigue.

There is a range of stakeholders in the maritime transport industry; several were invited to participate in this study. Table 2 gives an overview of the number of stakeholders involved.

The stakeholders were asked to bear the following question in mind when using the fundamental scale to judge between the elements in the benefits model (Fig. 3): "Which of the following measures have the strongest grounding avoidance effect? Compare the measures in relation to their ability to lower the probability of grounding. The context of the measures is the bridge management team (BMT)". Furthermore, the context for all the models is a ship on a voyage lasting at least $24 \mathrm{~h}$ and containing personnel working in shifts.

For the cost model (Fig. 4), the stakeholders were asked to consider the decision elements in relation to perceived or expected costs for shipowners. The costs are defined as the sum of planning up to and including the implementation of the various measures. The benefits model and the cost model (models 1 and 2) consist of the same elements, so the ratio of their weights can be calculated. In the fatigue model (Fig. 5), which does not have any direct link to the former two models, the stakeholders were asked to compare the elements in relation to the perceived impact on human fatigue (one of the factors in models 1 and 2).

If the comparisons had higher inconsistency than $10 \%$, the stakeholders were contacted to reconsider their responses. If inconsistency was below the acceptable level, their answers were included in the present study; otherwise, their answers were rejected. Four of the replies to the benefits model were rejected, while one reply to the cost model was rejected. For the fatigue model, eight replies were rejected. A stakeholder may thus have had good consistency in one model, but not in another. For example, answers from a stakeholder may be included in the benefits model, but not in the cost model. In the end, answers from 29 stakeholders were included in the AHP process.

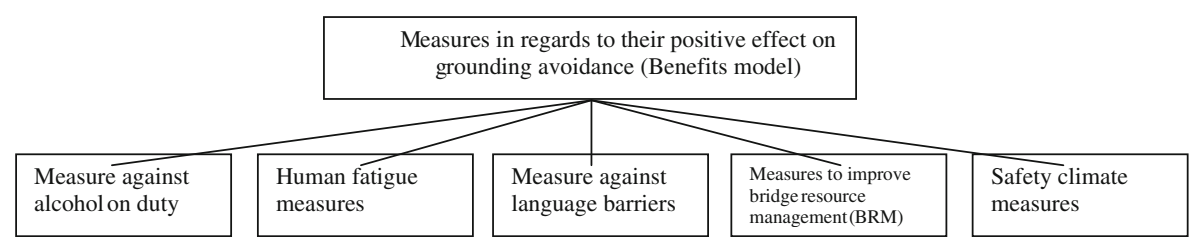

Fig. 3 AHP model 1 of measures for lowering the probability of groundings (benefits model) 


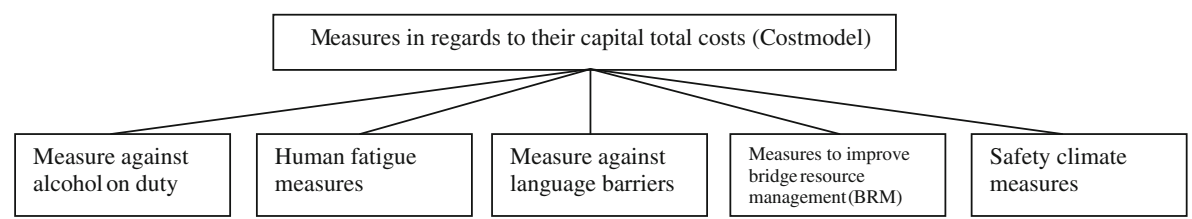

Fig. 4 AHP model 2 of the costs of measures for lowering the probability of groundings (cost model)

\section{Results}

\subsection{The AHP results}

Tables 3 and 4 show the idealized weight of eigenvectors (relative priorities) obtained from the stakeholders' elicitation for the benefits and cost models. The present study made use of the software program SuperDecisions, version 2.2.3 (Adams and Creative Decision Foundation 2012) to calculate the eigenvectors. The idealizing was done by dividing each element's vector of priority value with the largest vector of priority value, so that the decision elements with the highest priority got the value 1.000. For instance, in the last column of Table 3, the element with the second highest priority is "human fatigue measures" with a value of $0.779(0.254 / 0.326)$. This means that the human fatigue measures have $77.9 \%$ grounding avoidance effect compared to "measure to improve BRM", which has the priority value 1.000; the "safety climate measure" has $56.4 \%$ grounding avoidance effect, and so on.

In Table 3, high values are preferred, as they indicate higher perceived benefits. In Table 4, low values are preferred, since they indicate lower costs. Table 5 shows the cost-benefit $(\mathrm{C} / \mathrm{B})$ ratio of the weight values. A low $\mathrm{C} / \mathrm{B}$ ratio $(<1)$ indicates a high gain compared to the investment, while a high ratio $(>1)$ indicates that the stakeholder perceive costs to have a higher value than benefits.

Table 6 shows the idealized weight of the eigenvector from the fatigue model. Decision elements with low values are preferable, as they reflect the stakeholders' preferences with respect to contributions to human fatigue.

The results show that the stakeholders consider that measures to ensure adequate BRM lead to the strongest grounding avoidance effect among the available measures (Table 3). However, the stakeholders are divided over costs related to "measures to improve BRM" (Table 4). Consultants and ship companies/organizations believe that "BRM measures" is one of the most costly measures, while the others believe they are relatively inexpensive. All stakeholders believe that the costs are lower than the benefits involved $(\mathrm{C} / \mathrm{B}<1)$ for $\mathrm{BRM}$ measures (Table 5). The academics have a cost $\mathrm{C} / \mathrm{B}$ ratio of 0.316 , and the authorities have a ratio of 0.365 . The remaining stakeholders have a more moderate ratio.

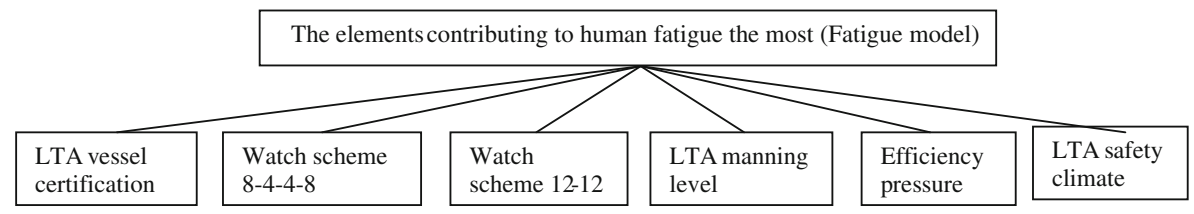

Fig. 5 AHP model 3 of important elements contributing to human fatigue (fatigue model) 
Table 2 The stakeholders involved in the weighting process of AHP

Stakeholder

Number of persons

Academics (Norway, Finland and Sweden)

7

Consultants and insurers (Norway)

6

Authorities (The Norwegian Coast Guard, Norwegian Maritime Authority,

The Norwegian Coastal Administration)

Ship companies and organizations (Norway, Denmark)

6

Seafarers (Norway, Finland, UK)

Total

6

For measures against human fatigue, again, consultants and ship companies/ organizations stand out, deeming that such measures are not vital, while the other stakeholders regard them as the most important measures for grounding avoidance. Overall, the measures related to human fatigue have a high $\mathrm{C} / \mathrm{B}$ ratio. All stakeholders, with the exception of the consultants and insurers, believe the costs to be higher than the benefits; academics regarded the costs to be 2.2 times higher than the benefits.

The stakeholders perceive measures related to safety climate to have a moderate effect on groundings. However, consultants and ship companies/organizations regard their costs to be high. All stakeholders, with the exception of the academics, believe their cost-benefit ratio to be higher than one $(\mathrm{C} / \mathrm{B}>1)$.

The stakeholders also consider measures against language barriers to have relatively little importance regarding the probability of grounding. Neither of their costs is regarded as high. Still, the cost-benefit ratio for all the stakeholders is above $1(\mathrm{C} / \mathrm{B}>1)$.

Measures against abuse of alcohol score high in the benefits model (Table 3 ) and low in the cost model (Table 4). As such, they had the lowest C/B ratio. Summing up, only the BRM measures and measures against alcohol abuse have a $\mathrm{C} / \mathrm{B}$ ratio $<1$ (Table 5).

Table 3 The positive effect of measures on grounding avoidance (Benefits model). The Eigenvector weight is presented as ideals. The vector of priorities is given in blankets

\begin{tabular}{lllllll}
\hline Measure & Academics & $\begin{array}{l}\text { Consultants } \\
\text { and insurers }\end{array}$ & Authorities & $\begin{array}{l}\text { Ship companies } \\
\text { and org. }\end{array}$ & Seafarers & Total \\
\hline $\begin{array}{c}\text { Measures to improve } \\
\text { bridge resource } \\
\text { management (BRM) }\end{array}$ & 1.000 & 1.000 & 0.990 & 1.000 & 0.801 & 1.000 \\
Human fatigue measures & 0.398 & 0.470 & 1.000 & 0.285 & $(0.234)$ & $(0.326)$ \\
& $(0.167)$ & $(0.196)$ & $(0.288)$ & $(0.146)$ & $(0.292)$ & $(0.254)$ \\
Safety climate measures & 0.598 & 0.530 & 0.552 & 0.294 & 0.582 & 0.564 \\
& $(0.251)$ & $(0.221)$ & $(0.159)$ & $(0.151)$ & $(0.170)$ & $(0.184)$ \\
Measure against alcohol & 0.202 & 0.204 & 0.597 & 0.246 & 0.664 & 0.396 \\
on duty & $(0.085)$ & $(0.085)$ & $(0.172)$ & $(0.126)$ & $(0.194)$ & $(0.129)$ \\
Measure against & 0.431 & 0.194 & 0.333 & 0.123 & 0.373 & 0.328 \\
language barriers & $(0.181)$ & $(0.081)$ & $(0.096)$ & $(0.063)$ & $(0.109)$ & $(0.107)$ \\
Consistency Ratio (CR) & 0.07 & 0.04 & 0.01 & 0.11 & 0.02 & 0.01 \\
\hline
\end{tabular}


Table 4 Measures in regard to their total capital costs (Costs model). The eigenvector weight is presented as ideals. The vector of priorities is given in blankets

\begin{tabular}{lllllll}
\hline Measure & Academics & $\begin{array}{l}\text { Consultants } \\
\text { and insurers }\end{array}$ & Authorities & $\begin{array}{l}\text { Ship companies } \\
\text { and org. }\end{array}$ & Seafarers & Total \\
\hline $\begin{array}{c}\text { Measures to improve } \\
\text { bridge resource } \\
\text { management (BRM) }\end{array}$ & 0.356 & 1.000 & 0.224 & 0.986 & 0.362 & 0.726 \\
Human fatigue measures & 1.000 & 0.452 & 1.000 & 0.504 & $(0.142)$ & $(0.217)$ \\
& $(0.374)$ & $(0.137)$ & $(0.464)$ & $(0.176)$ & $(0.392)$ & $(0.299)$ \\
$\begin{array}{c}\text { Safety climate measures } \\
\text { Measure against alcohol }\end{array}$ & 0.511 & 0.908 & 0.381 & 1.000 & 0.533 & 0.716 \\
on duty & $(0.191)$ & $(0.275)$ & $(0.177)$ & $(0.349)$ & $(0.209)$ & $(0.214)$ \\
Measure against language & 0.601 & 0.353 & 0.179 & 0.181 & 0.222 & 0.264 \\
barriers & $(0.537)$ & $(0.107)$ & $(0.083)$ & $(0.063)$ & $(0.087)$ & $(0.079)$ \\
Consistency Ratio (CR) & 0.03 & 0.587 & 0.369 & 0.198 & 0.434 & 0.639 \\
\hline
\end{tabular}

Regarding the human fatigue model, all stakeholders have a strong belief that LTA manning levels contribute most to human fatigue in the BMT (Table 6). The ship companies and organizations also believe that efficiency pressure contributes strongly to human fatigue. LTA manning levels contribute relatively much higher to human fatigue than the other five decision elements. The stakeholders also believe that the $8-4$ 4-8 watch scheme is better than 12-12 scheme in regard to human fatigue.

\section{Discussion and conclusions}

Various measures for reducing the probability of ship grounding are considered in this article. It is not straightforward to give a simple answer to which of the five measures

Table 5 The cost-benefit ratio of the vector of priorities for each measure

\begin{tabular}{|c|c|c|c|c|c|c|}
\hline \multirow[b]{2}{*}{ Measure } & \multicolumn{6}{|c|}{ Cost-benefit ratio } \\
\hline & Academics & $\begin{array}{l}\text { Consultants } \\
\text { and insurers }\end{array}$ & Authorities & $\begin{array}{l}\text { Ship companies } \\
\text { and org. }\end{array}$ & Seafarers & Total \\
\hline $\begin{array}{l}\text { Measures to improve } \\
\text { bridge resource } \\
\text { management (BRM) }\end{array}$ & 0.316 & 0.726 & 0.365 & 0.669 & 0.604 & 0.666 \\
\hline Human fatigue measures & 2.242 & 0.696 & 1.610 & 1.203 & 1.344 & 1.174 \\
\hline Safety climate measures & 0.762 & 1.242 & 1.114 & 2.315 & 1.227 & 1.161 \\
\hline $\begin{array}{l}\text { Measure against alcohol } \\
\text { on duty }\end{array}$ & 0.887 & 1.271 & 0.488 & 0.501 & 0.452 & 0.611 \\
\hline $\begin{array}{l}\text { Measure against language } \\
\text { barriers }\end{array}$ & 2.976 & 2.193 & 1.786 & 1.081 & 1.546 & 1.795 \\
\hline
\end{tabular}


Table 6 Elements causing the most human fatigue in BMT. The eigenvector weight is presented as ideals. The vector of priorities is given in blankets

\begin{tabular}{lllllll}
\hline Measure & Academics & $\begin{array}{l}\text { Consultants } \\
\text { and insurers }\end{array}$ & Authorities & $\begin{array}{l}\text { Ship companies } \\
\text { and org. }\end{array}$ & Seafarers & Total \\
\hline LTA manning level & 1.000 & 1.000 & 1.000 & 0.873 & 1.000 & 1.000 \\
& $(0.440)$ & $(0.536)$ & $(0.482)$ & $(0.206)$ & $(0.303)$ & $(0.422)$ \\
Watch scheme & 0.270 & 0.254 & 0.280 & 0.835 & 0.640 & 0.382 \\
12-12 & $(0.119)$ & $(0.136)$ & $(0.135)$ & $(0.197)$ & $(0.194)$ & $(0.161)$ \\
LTA safety climate & 0.398 & 0.192 & 0.334 & 0.572 & 0.475 & 0.346 \\
& $(0.175)$ & $(0.103)$ & $(0.161)$ & $(0.135)$ & $(0.144)$ & $(0.146)$ \\
Efficiency pressure & 0.352 & 0.207 & 0.114 & 1.000 & 0.297 & 0.265 \\
& $(0.155)$ & $(0.111)$ & $(0.055)$ & $(0.236)$ & $(0.090)$ & $(0.112)$ \\
LTA vessel & 0.150 & 0.114 & 0.207 & 0.381 & 0.416 & 0.190 \\
certifications & $(0.066)$ & $(0.061)$ & $(0.100)$ & $(0.090)$ & $(0.126)$ & $(0.080)$ \\
Watch scheme & 0.100 & 0.099 & 0.141 & 0.581 & 0.472 & 0.187 \\
8-4-4-8 & $(0.044)$ & $(0.053)$ & $(0.068)$ & $(0.137)$ & $(0.143)$ & $(0.079)$ \\
Consistency ratio & 0.03 & 0.04 & 0.02 & 0.02 & 0.01 & 0.01 \\
$\quad(C R)$ & & & & & & \\
\hline
\end{tabular}

(related to the BRM, human fatigue, safety climate, alcohol abuse and language barriers) the decision-maker should prioritize. However, human fatigue measures are considered the most expensive to implement by the stakeholders; the second most expensive are the BRM measures; third, the language barriers measures; fourth, the safety climate measures; and lastly, alcohol abuse.

When choosing which measure to implement, the decision-maker has to keep in mind various consequences. Weighing the consequences of the different choices can be a difficult task. The AHP method gives the decision-makers an overview of the choices available and the stakeholders' related attitudes to them. This article demonstrates how AHP can be used for inputs to cost-benefit studies.

In summary, the results of the study reveal that stakeholders consider human fatigue as having a relatively strong effect on the probability of ship grounding. The human fatigue measures have the second highest priority when the stakeholders are asked about the most effective measure to reduce the probability of ship grounding, but the human fatigue measure still gets a $\mathrm{C} / \mathrm{B}$ ratio $>1$. However, the stakeholders also regard the costs related to human fatigue measures as being higher than the benefits of reducing the probability of ship grounding. Also, the stakeholders participating in this study mostly come from north-west Europe, where the costs are relatively high. Although the maritime industry operates in the global market, it may still not be straightforward to generalize the $\mathrm{C} / \mathrm{B}$ ratios.

Furthermore, the results are not controlled for known fatigue-related factors such as the short voyages, circadian effects, etc. Vessels factors, such as the age and the size of the ship, are not part of the equation. The study gives a broad picture of the situation for all ships on a voyage of at least $24 \mathrm{~h}$. Therefore, further research should be done on specific types of ships and circumstances. 
The stakeholders' opinion about human fatigue measures being too costly might help understand why fatigue is still a widespread phenomenon in the maritime industry. However, it must be said that there are some differences between the stakeholders. The consultants, the ship companies and organizations believe the human fatigue measure costs to be lower than what the academics, authorities and seafarers believe (Table 4). Only the consultants regard the fatigue measures to have a significant cost-benefit ratio (i.e. <1) (Table 5).

Consequently, measures for reducing language barriers score poorly for both benefits (low benefits) and costs (high costs). The costs of improving language skills outweigh the benefits by a factor of almost 1.8 .

In the stakeholders' opinion, the watch scheme 8-4-4-8 generates less human fatigue than the 12-12 watch scheme. All stakeholders have a strong belief that among the decision elements considered, adequate manning levels are most important to avoid human fatigue. Adequate manning is clearly regarded as the most important element contributing to human fatigue. More research should be done on the effect LTA manning levels have on human fatigue and the probability of ship grounding.

The AHP study indicates differences between the stakeholders regarding the perceived benefits and costs of some of the measures. It is well known that the risk perception of stakeholders is influenced by their social networks and social interactions. There is a tendency to show solidarity to their own communities, and they often attempt to rigidly place themselves well within the "agreed upon" reality in their communities (Recchia 1999). Motivational bias may also play a role; it can occur when the expert has something to gain or lose in the outcome of the ongoing assessment. Needless to say, the research has little to say about the motivational biases, but the analyst should be aware of this fact (Vick 2002). The AHP method deals with this bias by searching for any inconsistencies in the answers.

In general, it is recommended that studies should include stakeholders who differ from each other in terms of viewpoint and knowledge in order to minimize redundant information and maximize the effectiveness of aggregation (Clemen and Winkler 1999). By including various stakeholders, the study attempts to elicit the common beliefs of the maritime industry. Also, the number of stakeholders or experts involved in this study, as well as the high consistencies in their answers, indicate the robustness of the analysis. Still, the differences between the stakeholders highlighted in this study should be subjected to further research.

Finally, the numbers of measures investigated are only five due to AHP and its practical limitations. Although the five measures were chosen carefully to cover important known issues linked to human factors and the probability of grounding, future research should consider including more measures.

The following main conclusions can be drawn from the study in this article:

1. Among the five measures (related to alcohol abuse, bridge resource management, human fatigue, safety climate and language barriers), measures against alcohol abuse are considered to be the most cost-benefit efficient alternative to implement for shipowners.

2. In general, the stakeholders in the maritime community deem human fatigue measures to have a high benefit (prioritized second), but the costs of implementing them are deemed to be higher (highest costs). 
3. The watch scheme $8-4-4-8$ is considered less fatiguing than the $12-12$ scheme by the stakeholders.

4. The stakeholders regard LTA manning on the bridge of a ship to be the most crucial element with respect to generating human fatigue.

\section{Annex}

Table 7 Below are the explanations of the elements included in the study with their examples and possible measures, as explained to the stakeholders. It was stated that the measures were not all- inclusive, and were meant to serve as examples

\begin{tabular}{|c|c|c|}
\hline Concept & Explanation & Possible measures \\
\hline Alcohol & $\begin{array}{l}\text { Even low alcohol exposure significantly } \\
\text { impairs the performance of the maritime } \\
\text { bridge crew. Alcohol has a similar effect } \\
\text { on human cognitive capacities as fatigue. } \\
\text { A period of sustained wakefulness of } \\
18 \mathrm{~h} \text { can be comparable to a blood alcohol } \\
\text { concentration (BAC) of } 0.05 \% \text {. If sleep } \\
\text { deprivation continues for } 24 \mathrm{~h} \text {, the of fatigue } \\
\text { is equal to a BAC level of } 0.10 \% \text {.Use of } \\
\text { alcohol also significantly impairs the visual } \\
\text { search and the solving of navigational } \\
\text { problems (Marsden and Leach } 2000 \text { ) }\end{array}$ & $\begin{array}{l}\text { No alcohol allowed on-board; frequent } \\
\text { BAC checks; severe consequences } \\
\text { if detected with blood alcohol } \\
\text { concentration on duty }\end{array}$ \\
\hline Fatigue & $\begin{array}{l}\text { A definition of maritime human fatigue is } \\
\text { "a biological drive for recuperative rest" } \\
\text { Fatigue can be classified as physical or } \\
\text { mental. Mental fatigue is believed to be } \\
\text { psychological in nature, whereas physical } \\
\text { fatigue is considered synonymous with } \\
\text { muscle fatigue. Both physical and mental } \\
\text { fatigue causes decline in alertness, mental } \\
\text { concentration and motivation. Fatigue } \\
\text { decreases the speed of cognitive processing, } \\
\text { and thus the major symptom of mental } \\
\text { fatigue is a general sensation of weariness, } \\
\text { increases in reaction time, lower vigilance } \\
\text { and disinclination for any kind of activity. } \\
\text { Psychological distress is shown to be most } \\
\text { aggravated in workers who face high } \\
\text { demands in their jobs, e.g. excessive work } \\
\text { load, confined spaces and poor thermal } \\
\text { conditions }\end{array}$ & $\begin{array}{l}\text { Lower the efficiency pressure; increase } \\
\text { the rest times; predictable working } \\
\text { hours; increase number of holidays; } \\
\text { increase the manning level on the } \\
\text { bridge; better ergonomic designs }\end{array}$ \\
\hline $\begin{array}{l}\text { Bridge resource } \\
\text { management } \\
(\mathrm{BRM})\end{array}$ & $\begin{array}{l}\text { Bridge resource management draws its } \\
\text { inspiration from the airline industry, which } \\
\text { found an alarming number of accidents } \\
\text { happened despite prior warning from the } \\
\text { equipment or crew to the officer in charge. } \\
\text { The BRM introduces the concept of a } \\
\text { navigation team to ship crew and frames } \\
\text { their decision-making process towards } \\
\text { establishing watch conditions during the }\end{array}$ & $\begin{array}{l}\text { BRM courses; stricter company } \\
\text { policies obliging BRM application; } \\
\text { BRM campaigns }\end{array}$ \\
\hline
\end{tabular}


Table 7 (continued)

\begin{tabular}{|c|c|c|}
\hline Concept & Explanation & Possible measures \\
\hline & $\begin{array}{l}\text { course of the voyage. Bridge team } \\
\text { management techniques emphasize } \\
\text { decision-making in the bridge team, based } \\
\text { upon conditions related to workload and } \\
\text { potential threats to the vessel. The BRM } \\
\text { seeks to define the individual task and } \\
\text { responsibilities of the various bridge } \\
\text { team members while developing a common } \\
\text { situational awareness to prevent individual } \\
\text { errors }\end{array}$ & \\
\hline Safety climate & $\begin{array}{l}\text { An important fatigue influencing factor is } \\
\text { safety climate, which reflects the attitudes, } \\
\text { beliefs, perception and values that persons } \\
\text { share in relation to safety at all levels of the } \\
\text { organization. A safety climate is only one } \\
\text { aspect of the safety culture in an organization, } \\
\text { which can be defined as a constructed system } \\
\text { of meaning through which the hazards of the } \\
\text { world are understood. There is, however, a } \\
\text { lack of universal consensus regarding the } \\
\text { term safety culture and safety climate. Often, } \\
\text { the terms are used interchangeably in the } \\
\text { literature. Safety culture can be defined as } \\
\text { a set of attitudes, perceptions, competencies } \\
\text { and patterns of behaviour in an organization, } \\
\text { which encompasses "how people feel" about } \\
\text { safety and safety management systems. This } \\
\text { feeling is the safety climate, which can be } \\
\text { measured subjectively through the use of, for } \\
\text { example, questionnaires }\end{array}$ & $\begin{array}{l}\text { Level of employee empowerment; } \\
\text { higher management involvement } \\
\text { and interest; the rewarding system; } \\
\text { safety information; investment in } \\
\text { safety and safety oriented } \\
\text { procedures }\end{array}$ \\
\hline $\begin{array}{l}\text { Language } \\
\text { barriers }\end{array}$ & $\begin{array}{l}\text { Many cultures and nationalities work together } \\
\text { in the maritime transport industry. This can } \\
\text { create language barriers and increase fatigue } \\
\text { levels on-board. Effective and clear } \\
\text { communication between the vessel traffic } \\
\text { services (VTS) and seafarers, vessels and } \\
\text { ships needs to be in place }\end{array}$ & $\begin{array}{l}\text { Technical language courses; recruit } \\
\text { higher-qualified personnel }\end{array}$ \\
\hline
\end{tabular}

\section{References}

Adams B, Creative Decision Foundation (2012) SuperDecisions-AHP software. Creative Decision foundation, Pittsburgh

Åkerstedt T, Kecklund G, Gillberg M, Lowdan A, Axelsson J (2000) Sleepiness and days of recovery. Transp Res Part F 3:251-261

Anderson P, Nicholls S, Noonan S (2003) 'Cracking the Code'-the relevance of the ISM Code and its impact on shipping practices. The Nautical Institute, London

Arslan O, Turan O (2009) Analytical investigation of marine causalities at the Strait of Istanbul with SWOT-AHP method. Marit Policy Manag 36(2):131-145

Aziz IJ (1990) A post-evaluation of the Trans-Sumatra highway project. Eur J Oper Res 48:38-48

Barnett ML (2005) Searching for the root causes of maritime casualties-individual competence or organizational culture? WMU J Marit Aff 4(2):131-145 
Blom E (2006) Is the pilot a part of the bridge team? The fraser river pilots, vol 2013. Safety Service. http://members.shaw.ca/riverpilot35/team.htm, Accessed 23 August 2013, Vancouver, Canada

Bûyûkôzkan G, Cifci G, Gûleryûz S (2011) Strategy analysis of healthcare service quality using fuzzy AHP methodology. Expert Syst Appl 38:9407-9424

Cahill CRA (2002) Strandings and their causes. The Nautical Institute, Southall, Middlesex

Celik M, Cebi S (2009) Analytical HFACS for investigating human errors in shipping accidents. Accid Anal Prev 41:66-75

Chauvin C, Lardjane S, Morel G, Clostermann J-P, Langard B (2013) Human and organizational factors in maritime accidents: analysis of collisions at sea using the HFACS. Accid Anal Prev 59:26-37

Clayton WA, Wright M (1993) Benefit cost analysis of riverboat gambling. Math Comput Model 17(4/ 5):187-194

Clemen RT, Winkler RL (1999) Combining probability distributions from experts in risk analysis. Risk Anal 19(2):187-203

Cuculic D, Bosnar A, Stemberga V, Coklo M, Nikolic N, Grgurevic E (2009) Interpretation of blood alcohol concentration in maritime accidents-a case report. Forensic Sci Int Suppl Ser 1:35-37

Desmond PA, Hancock PA (2001) Active and passive fatigue states. In: Desmond PA, Hancock PA (eds) Stress, Workload and Fatigue. Lawrence Erlbaum Associates, London, pp 455-465

Dorrian J, Baulk SD, Dawson D (2011) Work hours, workload, sleep and fatigue in Australian Rail Industry employees. Appl Ergon 42:202-209

Elvik R (2001) Cost-benefit analysis of road safety measures: applicability and controversies. Accid Anal Prev 33(1):9-17

Ficca G, Axelsson J, Mollicone DJ, Muto V, Vitiello MV (2010) Naps, cognition and performance. Sleep Med Rev 14:249-258

Graham CAE (2009) Maritime security and seafarers' welfare: towards harmonization. WMU J Marit Aff 8(1):71-87

Greenberg R (2007) A Quantitative safety model of systems subject to low probability high consequence accidents. University of South Australia, PhD thesis

Gujiter Dd, Hageman E (2010) A new and easy method for cost-benefit analysis of noise measures along highways and railways. Proceedings of the 39th International congress and exposition on noise control engineering

Hänninen M (2008) Analysis of human and organizational factors in marine traffic risk modelling. Literature review. Series AM. Helsinki University of Technology. Faculty of engineering and architecture. Department of applied mechanics, Espoo

Health \& Safety Executive (2005) A review of safety culture and safety climate literature for the development of the safety culture inspection toolkit. Health and Safety Executive (HSE), Bristol

Howland J, Rohsenow DJ, Cote J, Gomez B, Mangione TW, Laramie AK (2001) Effects of low-dose alcohol exposure on simulated merchant ship piloting by maritime cadets. Accid Anal Prev 33:257-265

IMO (1999) Principles of safe manning. Resolution A.890(21). International Maritime Organization (IMO), London

IMO (2001) Guidance on fatigue mitigation and management, vol MSC/Circ.101. International maritime organization (IMO), London

IMO (2011) International Convention on Standards of Training, Certification and Watchkeeping for Seafarers, 1978 (STCW). Sales number: IC938E, vol 2012. International Maritime Organization (IMO), London

Lappalainen J (2008) Transforming maritime safety culture. Evaluation of the impacts of the ISM Code on maritime safety culture in Finland. Centre for maritime studies. University of Turku, Turku

Lu C-S, Tsai C-L (2008) The effects of safety climate on vessel accidents in the container shipping context. Accid Anal Prev 40:594-601

Lützhöft M, Thorslund B, Kircher A, Gillberg M (2007) Fatigue at sea — a field study in Swedish shipping. VTI Rapport 586A. VTI, Linköping

MacDonald R (2006) Safe manning of ships_-yesterday, today and tomorrow. WMU J Marit Aff 5(2):143-151

Macrae C (2009) Human factors at sea: common patterns of error in groundings and collisions. Marit Policy Manag 36(1):21-38

MAIB (2004) Bridge watchkeeping safety study, vol 1/2004. Marine Accident Investigation Branch, Southampton

Marsden G, Leach J (2000) Effects of alcohol and caffeine on maritime navigational skills. Ergonomics 43(1):17-26

Neal A, Griffin MA, Hart PM (2000) The impact of organizational climate of safety climate and individual behaviour. Saf Sci 34(1-3):99-109 
Perrow C (1984) Normal accidents. Princeton University Press, New Jersey

Progoulaki M, Roe M (2011) Dealing with multicultural human resources in a socially responsible manner: a focus on the maritime industry. WMU J Marit Aff 10:7-23

QinetiQ Centre (2006) The development of a fatigue/risk index for shiftworkers. MB Spencer, KA Robertson \& S Folkard, Simon Folkard Associates Ltd, London

Recchia V (1999) Risk communication and public perception of technological hazards, Volume 1. FEEM series on economics, energy, and environment. Fondazione Eni Enrico Mattei (FEEM), Nota di lavoro

Ridefelt P, Larsson A, Rehman J-u, Axelsson J (2010) Influences of sleep and the circadian rhythm on ironstatus indices. Clin Biochem 43:1323-1328

Rothblum AM, Wheal D, Withington S, Shappell SA, Wiegmann DA, Boehm W, Chaderjian M (2002) Human factors in incident investigation and analysis. US Coast Guard Research \& Development Centre, Houston, Texas

Saaty RW (1987) The analytic hierarchy process — what it is and how it is used. Math Model 9(3-5):161-176

Saaty TL (2001) Decision making for leaders. The analytic hierarchy process for decision in a complex world. RWS Publications, Pittsburgh, PA

Saaty TL (2004) Decision making - the analytic hierarchy and network processes (AHP/ANP). J Syst Sci Syst Eng 13(1):1-35

Saaty TL, Ozedemir MS (2003) Why the magic number seven plus or minus two. Math Comput Model 38:233-244

Saaty TL, Vargas LG (2006) Decision making with analytic network process. Economic, political, social and technological applications with benefits, opportunities, costs and risks. Springer, Pittsburgh, PA, USA

Schröder-Hinrichs JU, Baldauf M, Ghirxi KT (2011) Accident investigation reporting deficiencies related to organizational factors in machinery space fires and explosions. Accid Anal Prev 43(3):1187-1196

Schröder-Hinrichs J-U, Hollnagel E, Baldauf M (2012) From Titanic to Costa Concordia-a century of lessons not learned. WMU J Marit Aff 11:151-167

Seahealth (2010) Shipping and rest. How can we do better? Seahealth, Denmark

Smith A, Allen P, Wadsworth E (2006) Seafarer fatigue: the Cardiff research programme. Centre for Occupational and Health Psychology, Cardiff

Sneddon A, Mearns K, Flin R (2012) Stress, fatigue, situation awareness and safety in offshore drilling crews. Safety Sci 56:80-88. doi:10.1016/j.ssci.2012.05.027

Strahan C, Watson B, Lennonb A (2008) Can organizational safety climate and occupational stress predict work-related driver fatigue? Transp Res 11(6):418-426

Swift CAJ (2004) Bridge Team Management - A practical guide. Second edition edn. The Nautical Institute, Southall, Middlesex

Utne IB (2008) Are the smallest fishing vessels the most sustainable? - trade-off analysis of sustainability attributes. Mar Policy 32:465-474

Veisten K, Akhtar J (2010) Cost-benefit analysis of low-noise pavements: dust into the calculations. Int J Pavement Eng. doi:10.1080/10298436.2010.506537

Vick SG (2002) Degrees of belief: subjective probability and engineering judgment. ASCE Press. American Society of Civil Engineers, Reston, Virgina

Vidal L-A, Sahin E, Martelli N, Berhoune M, Bonan B (2010) Applying AHP to select drugs to be produced by anticipation in a chemotherapy compounding unit. Expert Syst Appl 37:1528-1534

Wedley WC, Choo EU, Schoner B (2001) Magnitude adjustment for AHP benefit/cost ratios. Eur J Oper Res 133:342-351

Wiegmann DA, Shapell SA (2003) A human error approach to aviation accident analysis - the human factors analysis and classification system. Ashgate Press, Surrey

Williamson A, Lombardi DA, Folkard S, Stutts J, Courtney TK, Connor JL (2009) The link between fatigue and safety. Accid Anal Prev 43:498-515

Xhelilaj E, Lapa K (2010) The role of human fatigue factor towards maritime casualties. Marit Transp Navig J 2(2):2065-2909, ISSN

Yang J, Shi P (2002) Applying analytic hierarchy process in firm`s overall performance evaluation: a case study in China. International Journal of Business 7(1):30-46

Zheng G, Zhu N, Tian Z, Chen Y, Sun B (2012) Application of a trapezoidal fuzzy AHP method for work safety evaluation and early warning rating of hot and humid environments. Saf Sci 50:228-239 